\title{
The Silty Clay Frozen Heave Characteristics Analysis of Frozen Shrinkage Phenomenon
}

\author{
Hui-Xin ZHAO ${ }^{1, a,{ }^{*}}$, Lu XIU ${ }^{2, b}$, Xiao-Li ZHAO ${ }^{3, c}$, Gui-Jun WANG ${ }^{4, d}$ \\ ${ }^{1,2}$ College of Water Conservancy and Electric Power, Heilongjiang University, Harbin, China \\ ${ }^{3}$ Hydrological Bureau, Daqing, Heilongjiang Province, China \\ ${ }^{4}$ Heilongjiang Provincial Hydraulic Construction Supervision Company, Harbin, China \\ aHuixin_zhao@126.com, bxiuluer@163.com, 515961118@qq.com, d1451737904@qq.com \\ ${ }^{*}$ Corresponding author
}

Keywords: Silty Clay, Frozen heave, Frozen Shrinkage, Moisture Migration.

\begin{abstract}
Frozen soil is a kind of special type of soil; it's sensitive to temperature and quite unstable. In seasonal permafrost region, the fluctuations of temperature will cause a large degree of influence on frozen heaving characteristics. This paper selects the highly frozen heave sensitive silty clay of the seasonal frozen soil region and does the frozen heaving characteristic test, in order to study of the occurrence of frozen shrinkage phenomenon and the frozen heaving characteristic of frozen shrinkage phenomenon. By the experimental study found that when the soil moisture content is low, the volume of water crystallizes into ice is not enough to fill the porosity of the soil body completely, cause the phenomenon of soil volume reduction. At the same time, the emergence of the phenomenon of frozen shrinking makes the soil temperature field a mutation, the soil moisture occurs crystallization in the case of soil inside moisture migration, frozen heave is negative, frozen heaving performance is relatively weak.
\end{abstract}

\section{Introduction}

Distribution of a large area of seasonal frozen ground in the northeast region of China, one of the common problems encountered in the process of engineering construction is frozen heaving damage in the seasonal frozen soil region [1]. Due to a long period of low-temperature environments, many hydraulic engineering, farmland, roads, bridges and other projects are subject to different degrees of frozen heave damage. On the frozen shrinkage problem, some scholars put forward two concepts that zeros frozen heave and freezing shrinkage, they think that when soil moisture content is low, if the groundwater influence is weak, frozen shrinkage phenomenon will occur [2]. Or at the beginning of the process of soil frozen heave, appear frozen stage [3]. In seasonal frozen soil region, warm soil layer is located in lower seasonal active layer, groundwater will supply the upper soil a lot, it's characteristics of freezing and melting cycle is unidirectional freezing, bi-directional melt. Aiming in Harbin city, Heilongjiang province, which is a typical seasonal frozen for the study area, select typical sensitivity of frozen heave soil-silty clay as the research object to analyze the frozen heave problem with frozen shrinkage phenomenon.

\section{The Frozen Shrinkage of the Soil}

\section{Frozen Shrinkage Phenomenon}

When the soil temperature is below zero degrees Celsius, the soil will be ice crystals, the cementation of ice crystals will cement the original water between mineral grains for ice cementation body, namely soil freezing. In the same conditions, due to different soil moisture contents, the soils can produce frozen heaving and freezing shrinkage two cases. Under normal circumstances, soil moisture will make the soil volume expansion in a certain degree, when the initial soil moisture content is lower than the initial moisture content of frozen heave, soil under the effect of low 
temperature appeared to be not expanded anti shrinkage phenomenon, namely the cold shrink phenomenon. When the soil moisture content is less than plastic limit, bound water content than capillary water and gravity water, this makes the soil freezing process; part of the increased volume after the water crystals of the soils isn' t enough to fill the gaps between the soil particles. However, due to soil particles effected by both cementation of ice crystals and thermal expansion and contraction, make soil particles austerity and glued each other, thus the macroscopic frozen shrinkage phenomenon appears. Therefore, too low moisture content is the major cause of producing frozen shrinkage phenomenon.

\section{The Difference between Frozen Shrinkage and Cold Shrinkage}

Many people believe that the frozen shrinkage phenomenon is cold shrunk phenomenon; it is not. The nature of the cold shrink phenomenon is the internal motion of the matter atoms, the cause is different from frozen shrinkage phenomenon. By indoor frozen heaving experiment shows, cold shrinkage phenomenon does not lead to soil samples produce cracks and damage, but frozen shrinkage will make part soil sample occurs tiny cracks, these cracks will threaten the overall stability of the soil structure seriously, and this is the biggest difference between them

\section{Experimental Materials}

This experiment chooses the material is silty clay, it's widely used in cold regions engineering, the sample material comes from seasonal frozen soil region Harbin Wanjia frost soil testing ground.In order to ensure the soil sample basic physical properties meet to the requirements of the frozen heaving test, conducting a series of routine soil tests before frozen heaving test.Measured the physical indicators as table 1 .

Tab. 1 Basic Physical Indicators of Silty Clay

\begin{tabular}{|c|c|c|c|c|c|c|c|c|c|c|c|}
\hline \multirow{3}{*}{ name } & \multicolumn{5}{|c|}{ The percentage of particles } & \multirow{3}{*}{$\begin{array}{c}\text { Proporti } \\
\text { on } \\
{\left[\mathrm{g} / \mathrm{cm}^{3}\right.} \\
\quad]\end{array}$} & \multirow{3}{*}{$\begin{array}{c}\text { Liquid } \\
\text { limit } \\
{[\%]}\end{array}$} & \multirow{3}{*}{$\begin{array}{c}\text { Plastic } \\
\text { limit } \\
{[\%]}\end{array}$} & \multirow{3}{*}{$\begin{array}{l}\text { Plasticity } \\
\text { index }\end{array}$} & \multirow{3}{*}{$\begin{array}{c}\text { Maximum } \\
\text { dry density } \\
{\left[\mathrm{g} / \mathrm{cm}^{3}\right]}\end{array}$} & \multirow{3}{*}{$\begin{array}{c}\text { Optim } \\
\text { um } \\
\text { moist } \\
\text { ure } \\
\text { conte } \\
\text { nt } \\
{[\%]}\end{array}$} \\
\hline & & Sand & & Silt & Clay & & & & & & \\
\hline & $\begin{array}{l}2 \sim \\
0.5\end{array}$ & $\begin{array}{l}0.5 \sim \\
0.25\end{array}$ & $\begin{array}{l}0.25 \sim \\
0.075\end{array}$ & $\begin{array}{c}0.075 \sim \\
0.005\end{array}$ & $\begin{array}{c}< \\
0.005\end{array}$ & & & & & & \\
\hline $\begin{array}{l}\text { Silty } \\
\text { clay }\end{array}$ & -- & -- & -- & 82.44 & 33.6 & 2.66 & 33.7 & 21.8 & 12.3 & 1.74 & 15.8 \\
\hline
\end{tabular}

The silt content of this kind soil up to $82.44 \%$, it's belong to the sensitivity frozen heaving soil. Through the test, the plastic limit of soil is $21.8 \%$, the initial frozen heave moisture content is in the range of $15.48 \%-18.75 \%$,it also verified the law that the clay plastic limit is larger than the initial heaving moisture content slightly. Because the salt content of this soil is very small, the impact of salt on the frost heave can be ignored.

\section{Experimental Equipment}

According to the test instruments requirement of Geotechnical Test ProceduresSL237-1999, the main instruments used in this test are XT5405FSC soil froze heave test chamber, data acquisition system for data taker85 intelligence data collector, the Chinese academy of science of cold and arid regions research institute developed RTD temperature sensor,FXg-81/ $\pm 30 \mathrm{~mm}$ differential displacement sensor, and electronics scale, mold, compactor, stripping for making samples.

\section{Experimental Scheme}

Made the soil sample for column of $10 \mathrm{~cm}$ in diameter, $10 \mathrm{~cm}$ in height insert the 7 pieces of temperature sensor into interval $1.5 \mathrm{~cm}$ soil sample; install the displacement sensor on top of the sample. During the experiment, adopt the continuous cooling model experiment; collect the data of temperature and displacement with the data collection device. The boundary of the experiment 
temperature is $-3^{\circ} \mathrm{C} \sim-9^{\circ} \mathrm{C}$, moisture levels range from $19 \%$ to $23 \%$, dry density range value is $1.50 \mathrm{~g}$ $/ \mathrm{cm} 3 \sim 1.58 \mathrm{~g} / \mathrm{cm} 3$. When the moisture content of soil sample is less than plastic limit, the macro will be frozen shrinkage phenomenon will occur macroscopically, take $-6^{\circ} \mathrm{C}$ for temperature, moisture content of $21 \%$ (this value is close to and below the plastic limit, which has the best representative), dry density is $1.54 \mathrm{~g} / \mathrm{cm} 3$ of soil samples as an example to analyze the frozen heave characteristics of frozen shrinkage phenomenon.

\section{Frozen Heaving Characteristics Analysis of Producing Frozen Shrinkage Phenomenon}

\section{Temperature Field Characteristic Analysis}

Drawing the below figure with the collected temperature test data of the data collecting instrument, as figure.1.



Fig. 1 Temperature Curve over Time of Continuous Cooling Mode $-6^{\circ} \mathrm{C}$

The figure shows the continuous cooling temperature changeable curve shows linear downward trend, then maintaining stable trend. The temperature field can be divided into two stages: the first stage of the cooling crystallization phase and the second stage of temperature stable phase. In the first stage, each layer soil sample temperature falls sharply, shows linear downward trend generally, and the dropping rate of the each layer soil sample temperature is same roughly, according to the proportion relationship of time and temperature, its average cooling rate is $0.42^{\circ} \mathrm{C} / \mathrm{h}$. The top layer soil temperature drop rate is smaller than the central layer; the bottom layer soil temperature drop rate is the biggest. Within $100 \sim 200$ minutes before starting cooling, topmost layer soil temperature drops than the near layer soil temperature faster, and the bottom layer soil temperature has the greatest reduction. In the beginning of this period, the soil moisture begins to crystallize in low temperatures environment and produce frozen heave, as the test proceeds, frozen heave is growing over time and reach the peak eventually. In the second stage, each layer soil sample temperature change little, the temperature maintains steady. Each layer soil samples temperature drops by layer, the most top temperature is highest, the most bottom temperature is lowest. The difference of the upper soil layers temperature drop is same roughly; the lower soil layers temperature drop difference is large.

\section{Frozen Shrinkage Characteristics Analysis}

Drawing the below figure with the collected displacement test data of the displacement transducer, as figure.2.

The figure shows that the frost heaving of soil samples produced a negative amount that is frozen shrinkage. The value of the frozen shrinkage amount is equal to the absolute value of the frost heave amount, and it's bigger than the changeable value which effected by the thermal expansion and 
contraction effect on soil. The process of producing frozen shrinkage amount will be divided into two steps: I frozen shrinkage stage, II stable stage. In frozen shrinkage stage, the frozen shrinkage amount shrank into linear ratio increases within the former1000 minutes of test; the maximum is close to $1.5 \mathrm{~mm}$. This phase corresponds to the first-order phase cooling crystallization of the temperature field, during this stage, due to the dropped temperature drop effect, the moisture of the inside soil generates the crystals, he lower moisture content makes the ice crystals can't fill up of the gaps between the soil particles, and the cementation in the process of crystallization makes gaps between the soil particles closer, the performance between soil particles becomes more dense, namely frozen shrinkage amount is growing bigger and bigger. In the stable stage, frozen shrinkage amount curve into a horizontal level, frozen shrank to maintain in the range of $1.4 \sim 1.6 \mathrm{~mm}$. This phase corresponds to the second-order phase temperature stable of the temperature field, when the temperature of the each layer soil samples reached stable, frozen shrinkage reached maximum and enters the stable phase, then frozen shrinkage amount remains basically unchanged.



Fig. 2 Amount of Frost Heave Curve over Time

\section{Characteristics of Moisture Migration}

Dividing the frozen heaving sample into eight layers intervals of $1.25 \mathrm{~cm}$, measure the moisture content of each layer soil samples, get moisture content distribution figure that along the height of soil sample, as shown in figure.3.

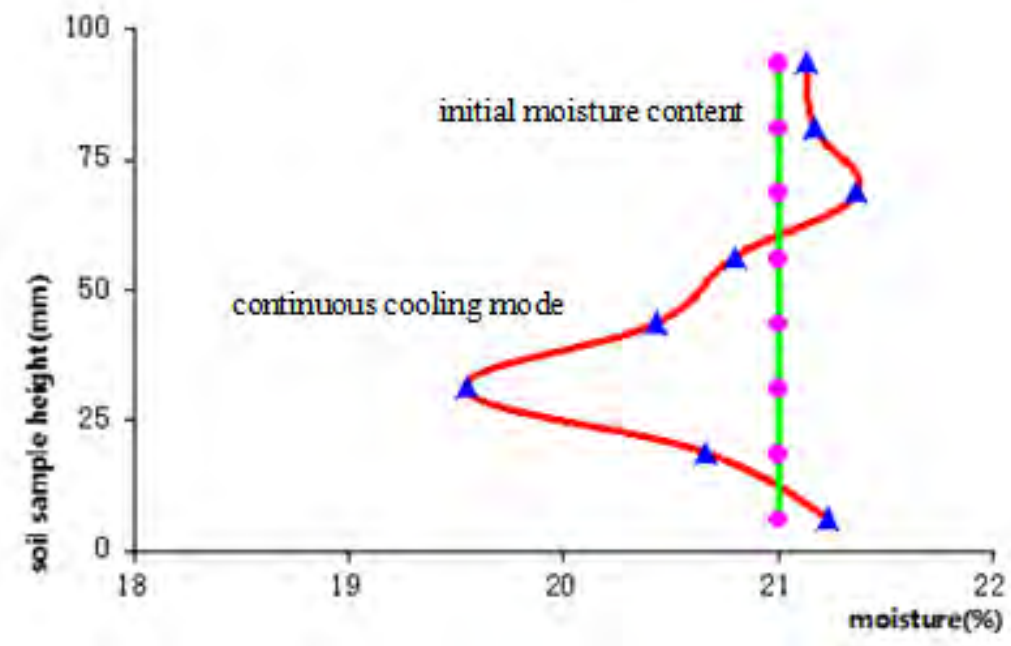

Fig. 3 Moisture Content Changeable Curve of Soil Samples with Height

The figure shows that, in the case of generating frozen shrinkage, the continuous cooling makes the inside soil moisture migration, the moisture content varies little value, within the scope of $19 \% \sim 22 \%$, characterized by the upper and lower moisture content is higher than the initial moisture content of soil sample, the middle and lower soil moisture content is lower than the initial moisture content, soil 
moisture content of $25 \mathrm{~mm}$ to $35 \mathrm{~mm}$ is close to $19.5 \%$, reach the soil sample moisture content minimum. According to the distribution of moisture content, it can be analyzed that the moisture content added value of the top and bottom was significantly higher than the middle and lower soil layers, it's relative to the soil sample inner moisture migrate to the frozen front and the gravity sink effect.

\section{Soil Sample Damage Characteristics Analysis}

The soil sample heave damage phenomenon in case of produce frozen shrinkage is not significant, it's rare to see large cracks, the small cracks that angle of about $15^{\circ}$ are more concentrated in the soil samples at $5 \sim 7 \mathrm{~cm}$,but these cracks do not tend to exhibit a certain degree of regularity. Due to cementation, the voids between soil particles become smaller and smaller, making between soil particles closer together. It can be analyzed that these cracks are formed as the result of soil particles are subject to tensile stress.

\section{Conclusion}

In the frozen heaving process, when the soil moisture content is low and lower than the plastic limit at a certain extent, It's tend to appear frozen shrinkage phenomenon, the soil occurs without swelling anti-shrink ,and expressed as a negative frost heave amount. The existence of the frozen shrinkage phenomena proves that not all soil freezing actions will cause an increase in the volume of soil. Frost heaving is a common manifestation of seasonal frozen soil regions, frozen heave damage is also a class of problems that cannot be ignored in the engineering, and it's often determines that the projects operate safely or not. Master of the frozen heave characteristics in the case of frozen shrinkage circumstances, it can be helpful to solve many engineering frozen damage problems of seasonal frozen soil region. In the future, the research in the field of seasonal frozen soil reg has its broad theoretical space and bright prospects.

\section{References}

[1]Qu Xiangmin, Zhang Hongyu. Introduction to engineering permafrost [M]. Harbin engineering university press, 2005.

[2]Tang Yiqun. Muddy clay under the action of artificial freezing frost heaving characteristics experimental study [J].Journal of geotechnical engineering.2009, 31(5):772-776.

[3]Tong Changjiang, Guan Nianfeng. Soil frost heave and frost damage prevention and control of buildings [M]. Beijing: Hydraulic and Hydroelectricity Press, 1985.

[4]ZHAO Huixin, ZHONG Jing,WANG Zhengjun. Experimental study on the influence of different cooling rate to frost heave of silty clay [J]. Advanced Materials Research Vols. 912-914, 2014: $136-140$

[5]ZHAO Huixin, WU Zhiqin, LI Zhaoyu. Experimental Study on Frost heave of Silty Clay in Seasonal Frost Soil Regions [J]. Procedia Engineering 28(2012)282-286. 